\title{
CULTURAL COMPETENCE CONTINUUM
}

\author{
Terry L. Cross, \\ National Indian Child Welfare Association
}

With kind permission from: The Regional Research Institute for Human Services, Portland State University: Focal Point: The Bulletin of The Research and Training Center on Family Support and Children's Mental Health, Fall, 1988, Cross, T., (c) 1988 by Regional Research Institute for Human Services, Portland State University.

Cultural competence is a set of congruent behaviors, attitudes and policies that come together in a system, agency, or professional and enable that system, agency, or professional to work effectively in cross-cultural situations. The word culture is used because it implies the integrated pattern of human behavior that includes thought, communication, actions, customs, beliefs, values, and institutions of a racial, ethnic, religious, or social group. The word competence is used because it implies having the capacity to function effectively. A culturally competent system of care acknowledges and incorporates-at all levels-the importance of culture, the assessment of cross-cultural relations, vigilance towards the dynamics that result from cultural differences, the expansion of cultural knowledge, and the adaptation of services to meet culturally unique needs.

Certainly the description of cultural competence seems idealistic. How can a system accomplish all of these things? How can it achieve this set of behaviors, attitudes, and policies? Cultural competence may be viewed as a goal toward which agencies can strive. Accordingly, becoming culturally competent is a developmental process. No matter how proficient an agency may become, there will always be room for growth. It is a process in which the system of care can measure its progress according to the agency's achievement of specific developmental tasks. As the tasks are defined the system will be guided toward progressively more culturally competent services. First, it is important for an agency to internally assess its level of cultural competence.

To better understand where one is in the process of becoming more culturally competent, it is useful to think of the possible ways of responding to cultural differences.

Imagine a continuum which ranges from cultural proficiency to cultural destructiveness. There are a variety of possibilities between these two extremes. Here we discuss five points along the continuum and the characteristics that might be exhibited at each position.

\section{Cultural Destructiveness}

The most negative end of the continuum is represented by attitudes, policies, and practices which are destructive to cultures and consequently to the individuals 
within the culture. The most extreme example of this orientation are programs which actively participate in cultural genocide- the purposeful destruction of a culture.

\section{Cultural Incapacity}

The next position on the continuum is one at which the system or agencies do not intentionally seek to be culturally destructive but rather lack the capacity to help minority clients or communities. The system remains extremely biased, believes in the racial superiority of the subdominant group and assumes a paternal posture towards "lesser" races. These agencies may disproportionately apply resources, discriminate against people of color on the basis of whether they "know their place" and believe in the supremacy of dominant culture helpers. Such agencies may support segregation as a desirable policy. They may act as agents of oppression by enforcing racist policies and maintaining stereotypes. Such agencies are often characterized by ignorance and an unrealistic fear of people of color. The characteristics of cultural incapacity include: discriminatory hiring practices, subtle messages to people of color that they are not valued or welcome, and generally lower expectations of minority clients.

\section{Cultural Blindness}

At the midpoint on the continuum the system and its agencies provide services with the express philosophy of being unbiased. They function with the belief that color or culture make no difference and that we are all the same. Culturally blind agencies are characterized by the belief that helping approaches traditionally used by the dominant culture are universally applicable; if the system worked as it should, all people - regardless of race or culture-would be serviced with equal effectiveness. This view reflects a well intended liberal philosophy; however, the consequences of such a belief are to make services so ethnocentric as to render them virtually useless to all but the most assimilated people of color.

Such services ignore cultural strengths, encourage assimilation, and blame the victims for their problems. Members of minority communities are viewed from the cultural deprivation model which asserts that problems are the result of inadequate cultural resources. Outcome is usually measured by how closely the client approximates a middle class non-minority existence. Institutional racism restricts minority access to professional training, staff positions and services.

Eligibility for services is often ethnocentric. For example, foster care licensing standards in many states restrict licensure of extended family systems occupying one home. These agencies may participate in special projects with minority populations when monies are specifically available or with the intent of "rescuing" people of color. Unfortunately, such minority projects are often conducted without community guidance and are the first casualties when funds run short. Culturally blind agencies suffer from a deficit of information and often lack the avenues through which they can obtain needed information. While these agencies often view them- 
selves as unbiased and responsive to minority needs, their ethnocentrism is reflected in attitude, policy, and practice.

\section{Cultural Pre-Competence}

Culturally competent agencies are characterized by acceptance and respect for difference, continuing self-assessment regarding culture, careful attention to the dynamics of difference, continuous expansion of cultural knowledge and resources, and a variety of adaptations to service models in order to better meet the needs of minority populations. The culturally competent agency works to hire unbiased employees, seeks advice and consultation from the minority community, and actively decides what it is and is not capable of providing to minority clients.

\section{Advanced Cultural Competence}

The most positive end of the scale is advanced cultural competence or proficiency. This point on the continuum is characterized by holding culture in high esteem. The culturally proficient agency seeks to add to the knowledge base of culturally competent practice by conducting research, developing new therapeutic approaches based on culture, and publishing and disseminating the results of demonstration projects. The culturally proficient agency hires staff who are specialists in culturally competent practice. Such an agency advocates for cultural competence throughout the system and improved relations between cultures throughout society.

In conclusion, the degree of cultural competence an agency achieves is not dependent on any one factor. Attitudes, policies, and practice are three major arenas where development can and must occur if an agency is to move toward cultural competence. Attitudes change to become less ethnocentric and biased. Policies change to become more flexible and culturally impartial. Practices become more congruent with the culture of the client from initial contact through termination. Positive movement along the continuum results from an aggregate of factors at various levels of an agency's structure. Every level of the agency (board members, policymakers, administrators, practitioners, and consumers), can and must participate in the process. At each level the principles of valuing difference, self-assessment, understanding dynamics, building cultural knowledge, and adapting practice can be applied. As each level makes progress in implementing the principles, and as attitudes, policies, and practices change, the agency becomes more culturally competent. 